\title{
PENGUKURAN FAKTOR RISIKO KETIDAKPATUHAN PENGOBATAN TUBERCULOSIS KHUSUSNYA HEALTH SYSTEM PADA PASIEN PINDAHAN
}

\author{
Leonov Rianto $^{1 *}$, Siti Aisyah ${ }^{1,2}$, Ika Agustina ${ }^{1}$ \\ ${ }^{1}$ Sekolah Tinggi Ilmu Kesehatan IKIFA \\ ${ }^{2}$ Departemen Farmasi RS Islam Jakarta Cempaka Putih \\ Email*: leonovrianto@ikifa.ac.id
}

Artikel diterima: 31 Agustus 2021; Disetujui: 3 September 2021

DOI: https://doi.org/10.36387/jiis.v6i2.747

\begin{abstract}
ABSTRAK
Pada kondisi Pandemi Covid-19 terjadi pemindahan rujukan pasien TBC dari Fasilitas kesehatan lain ke RS X yang mulai berlaku pada bulan April 2020. Salah satu dari lima faktor yang menyebabkan ketidakpatuhan pengobatan adalah health system. Sub faktor yang termasuk ke dalamnya adalah Health facility. Adanya pemindahan rujukan pasien ini diprediksi akan berhubungan dengan tingkat keberhasilan pengobatan TB. Penelitian ini bertujuan untuk menggambarkan faktor risiko health system pada ketidakpatuhan pengobatan pasien TB Resisten Obat (RO). Penelitian ini menggunakan pendekatan deskriptif kuantitatif. Populasi dalam penelitian ini adalah pasien TB RO. Teknik pengambilan sampel adalah total sampling. Kriteria inklusi pada penelitian ini adalah pasien TB RO yang masa pengobatan > 6 bulan serta telah terjadi pemindahan fasilitas Kesehatan ke RS X. Total sampel yang diperoleh sebanyak 35 responden. Hasil penelitian menunjukkan Faktor risiko health system pada ketidakpatuhan pengobatan pasien TB Resisten Obat (RO) rendah karena bagi pasien tidak mengalami kendala dalam hal jarak ke fasilitas Kesehatan serta tenaga Kesehatan yang kompeten dalam memberikan informasi seputar pengobatan pada pasien TB RO.
\end{abstract}

Kata kunci: Tuberkulosis, fasilitas kesehatan, tim kesehatan, sistem pelayanan kesehatan

\section{ABSTRACT}

During the Covid-19 pandemic, there was a transfer of TB patient referrals from other health facilities to the X Hospital which took effect in April 2020. One of the five factors that caused non-compliance with treatment was the health system. The sub factor included in this is Health facility. The transfer of patient referrals is predicted to be associated with the success rate of TB treatment. This study aims to describe the health system risk factors for non-adherence to treatment of drug-resistant TB (RO) patients. This study uses a quantitative descriptive approach. The population in this study were RO TB patients. The sampling technique is total sampling. The inclusion criteria in this study were RO 
TB patients whose treatment period was > 6 months and there had been a transfer of health facilities to The $X$ Hospital. The total sample obtained is 35 respondents. The results showed that the health system risk factor for non-adherence to treatment of Drug Resistant TB (RO) patients was low because patients did not experience problems in terms of distance to health facilities and competent health workers in providing information about treatment for ROTB patients.

Keywords: Tuberculosis, Health facility, Health Team, Health System

\section{PENDAHULUAN}

Indonesia merupakan salah satu negara yang memiliki beban tinggi terhadap penyakit Tuberculosis (TBC) menurut WHO tahun 20162020 (WHO, 2017). Posisi Indonesia terkait insiden kasus tertinggi di dunia menempati posisi ke-2 pada tahun 2016 dengan urutan India, Indonesia, China, Philipina, dan Pakistan. Angka prevalensi TBC Indonesia pada tahun 2017 sebesar 254 per 100.000 penduduk, secara global 120 kasus per 100.000 penduduk. Sedangkan di Permenkes No. 67 Tahun 2016 tentang Penanggulangan TBC nasional yaitu eliminasi pada tahun 2035 dan Indonesia bebas TBC tahun 2050 dengan indikator pencapaian sebesar 1 kasu per 100.000 penduduk (Kemenkes, 2018).

Angka keberhasilan (success rate) adalah jumlah semua kasus TBC yang sembuh dan pengobatan yang lengkap. Standar keberhasilan pengobatan yang ditetapkan oleh Badan kesehatan dunia WHO sebesar $85 \%$. Kondisi terkini terkait angka keberhasilan pengobatan pasien TBC semua kasus di Indonesia mengalami penurunan sejak tahun 2008 hingga 2017, yaitu dari $89,5 \%$ menjadi $85,1 \%$. Angka kesembuhan cendrung memiliki gap dengan angka keberhasilan pengobatan, sehingga kontribusi pasien yang sembuh terhadap angka keberhasilan pengobatan menurun dibandingkan tahun-tahun sebelumnya (Kemenkes, 2018).

Dalam bukunya menyatakan bahwa kepatuhan adalah fenomena multidimensi yang ditentukan oleh interaksi lima faktor, yang disebut "dimensi". Lima faktor utama yang mempengaruhi pasien dalam kepatuhan pengobatan antara lain patient-related, socioeconomic, health system, therapy-related, and condition related. Tipe efek yang 
digambarkan dalam setiap faktor terdiri dari 2 kategori yaitu faktor positif dimana dapat menstimulus kepatuhan pasien meningkat dan faktor negatif yang dapat menurunkan kepatuhan pasien (Ogundele et al., 2016).

Kejadian ketidakpatuhan pengobatan yang dilaporkan sangat bervariasi dari $4-92 \%$ di seluruh penelitian yang telah dilakukan (Haynes, 1976). Definisi ketidakpatuhan adalah pasien yang mengkonsumsi obat kurang dari $80 \%$ dosis yang diberikan (Anaam et al., 2012; Menzies et al., 2005; Trajman et al., 2010).

Pada kondisi Pandemi Covid19 terjadi pemindahan rujukan pasien TBC dari Fasilitas kesehatan lain ke RS X yang mulai berlaku pada bulan April 2020. Salah satu dari lima faktor yang menyebabkan ketidakpatuhan pengobatan adalah health system. Sub factor yang termasuk ke dalamnya adalah Health facility. Adanya pemindahan rujukan pasien ini diprediksi akan berhubungan dengan tingkat keberhasilan pengobatan TB. Penelitian ini bertujuan untuk menggambarkan faktor risiko health system pada ketidakpatuhan pengobatan pasien TB Resisten Obat (RO).

\section{METODE PENELITIAN}

Penelitian ini menggunakan pendekatan deskriptif kuantitatif. Populasi dalam penelitian ini adalah pasien TB RO. Teknik pengambilan sampel adalah total sampling. Kriteria inklusi pada penelitian ini adalah pasien TB RO yang masa pengobatan $>6$ bulan serta telah terjadi pemindahan fasilitas Kesehatan ke RS X. Kriteria Eksklusi pada penelitian ini adalah responden yang tidak bersedia mengisi kuesioner penelitian. Instrumen penelitian yang digunakan adalah kuesioner dengan 4 skala linkert dengan urutan penilaian dari besar ke kecil adalah sangat setuju, setuju, tidak setuju dan sangat tidak setuju.

\section{HASIL DAN PEMBAHASAN}

Jumlah responden pada penelitian ini sebanyak 35 orang dengan karakteristik seperti pada tabel 1 . 
Tabel 1. Karakteritik responden

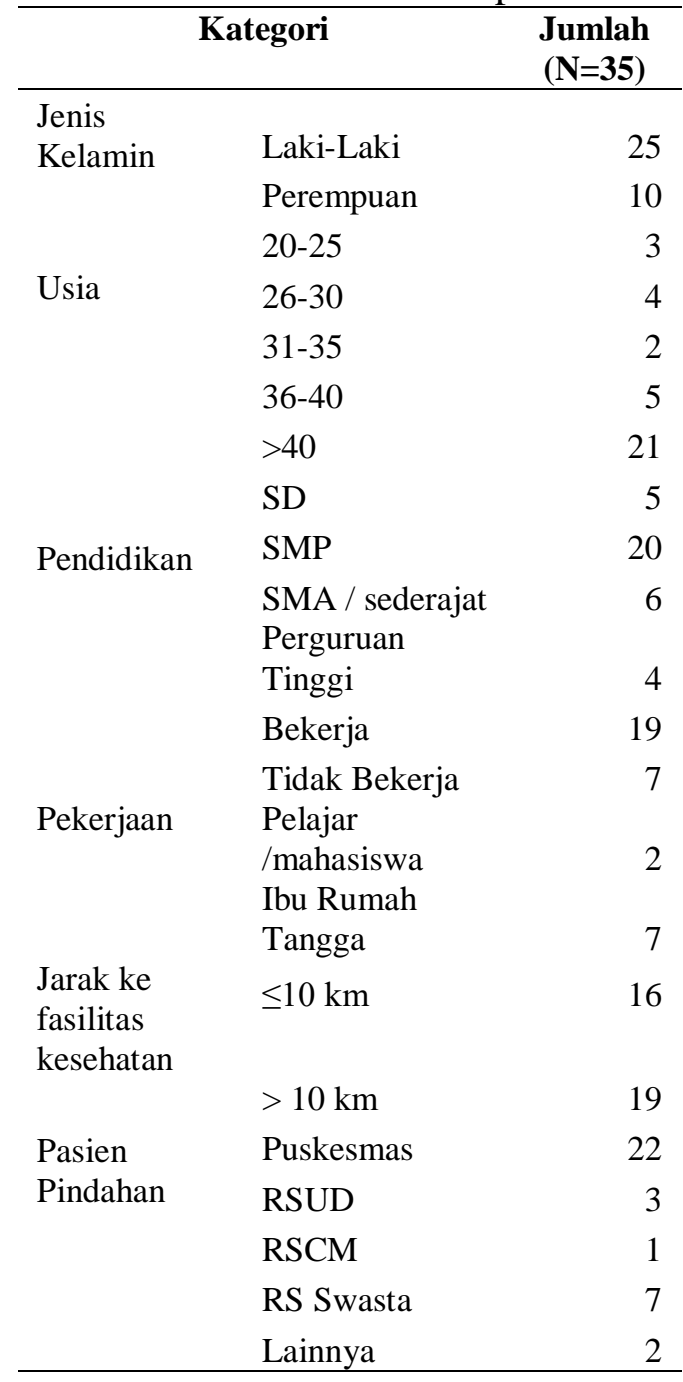

Berdasarkan tabel 1, pasien terbanyak berjenis kelamin laki-laki, usia lebih dari 40 tahun, tingkat Pendidikan SMP, jarak antara rumah ke fasilitas Kesehatan lebih dari 10 $\mathrm{km}$ serta banyak pasien pindahan dari Puskesmas.

Beberapa masalah yang timbul mengenai faktor health system adalah jarak ke fasilitas Kesehatan, keterjangkauannya serta fasilitas kendaraan yang dimiliki responden. Hasil pengukuran masalah tersebut ditampilkan pada Tabel 2.

Tabel 2. Lokasi Fasilitas Kesehatan

\begin{tabular}{ll}
\hline \multicolumn{1}{c}{ Pertanyaan } & $\begin{array}{c}\text { Rata-rata } \\
\text { nilai }\end{array}$ \\
\hline RS Susah dijangkau & 1.63 \\
Jarak RS Jauh & 2.31 \\
RS mudah dijangkau & 3.31 \\
$\begin{array}{l}\text { Saya memiliki kendaraan } \\
\text { untuk ke Fasilitas }\end{array}$ & \\
Kesehatan & 3.03 \\
\hline
\end{tabular}

Keterangan:

Setuju - Sangat Setuju $=3-4$

Sangat Tidak Setuju - Tidak Setuju= $1-2$

Berdasarkan data pada tabel 2 menunjukkan bahwa jarak yang jauh ke fasilitas Kesehatan bukan menjadi penghambat responden untuk datang menjalani pengobatan. Jika dilihat data karakteristik responden memiliki jarak ke fasilitas Kesehatan $>10 \mathrm{~km}$, namun jarak ini tidak menjadi alasan responden bahwa fasilitas Kesehatan sulit dijangkau, karena mayoritas responden menggunakan kendaraan pribadi untuk sampai ke fasilitas Kesehatan.

Selain lokasi fasilitas Kesehatan, tenaga Kesehatan yang berperan dalam melakukan pengobatan maupun pengawasan minum obat berperan terhadap 
keberhasilan pengobatan TB. Tabel 3 menunjukkan hasil evaluasi terhadap tenaga Kesehatan dalam memberikan pelayanan terhada pasien.

Tabel 2. Pelayanan Tenaga Kesehatan

\begin{tabular}{lc}
\hline \multicolumn{1}{c}{ Pertanyaan } & $\begin{array}{c}\text { Rata- } \\
\text { Rata } \\
\text { Nilai }\end{array}$ \\
\hline $\begin{array}{l}\text { Dokter memberi kesempatan } \\
\text { kepada saya untuk bertanya hal- } \\
\text { hal yang kurang saya mengerti }\end{array}$ & 3.4 \\
& \\
$\begin{array}{l}\text { Dokter mau memberi penjelasan } \\
\text { hal-hal yang kurang saya } \\
\text { mengerti }\end{array}$ & 3.54 \\
$\begin{array}{l}\text { Dokter mau menjawab } \\
\text { pertanyaan-pertanyaan saya }\end{array}$ & 3.43 \\
$\begin{array}{l}\text { Dokter tidak memberi } \\
\text { kesempatan saya bertanya }\end{array}$ & 1.66 \\
$\begin{array}{l}\text { Dokter tidak mau menjawab } \\
\text { pertanyaan-pertanyaan saya } \\
\text { Dokter tidak memberi saya } \\
\text { penjelasan atas hal-hal yang } \\
\text { kurang saya mengerti }\end{array}$ & 1.54 \\
$\begin{array}{l}\text { Saya dijelaskan tentang cara } \\
\text { minum obat yang diresepkan } \\
\text { Saya diberi penjelasan tentang } \\
\text { penjelasan yang diberikan oleh } \\
\text { tenaga kesehatan } \\
\text { terjadi }\end{array}$ & 3.463 \\
$\begin{array}{l}\text { Saya diberi tahu kapan saya harus } \\
\text { kontrol kembali } \\
\text { Penjelasan yang diberikan tentang } \\
\text { cara minum obat, efek samping } \\
\text { obat, dan jadwal kontrol kembali } \\
\text { mudah dipahami }\end{array}$ & 3.4 \\
& \\
\hline
\end{tabular}

Saya tidak dijelaskan efek 1.51 samping obat yang saya minum

Saya tidak diberi tahu kapan saya 1.46 harus kontrol kembali

Saya mengerti hal-hal yang telah dijelaskan oleh tenaga kesehatan

Penjelasan yang diberikan oleh tenaga kesehatan tidak jelas

\section{Keterangan:}

Setuju - Sangat Setuju $=3-4$ Sangat Tidak Setuju - Tidak Setuju= $1-2$

Pada tabel 3 menunjukkan bahwa tenaga Kesehatan telah memberikan pelayanan yang efektif sehingga pasien memahami bagaimana cara minum obat, waktu untuk kontrol kembali, serta seputar kondisi penyakit yang diderita pasien. Pada penelitian di Sierra Leone, Afrika menyebutkan bahwa fasilitas Kesehatan berpengaruh dengan kegagalan pengobatan, nilai OR yang diperoleh sebesar 1,19 (Lakoh, 2020). Penelitian pada wilayah Afrika lain seperti Ethiopia dan Nigeria juga menyebutkan bahwa fasilitas Kesehatan berpengaruh terhadap kepatuhan pengobatan dengan nilai OR 5,9 dan 2,76 (Oshi, 2014; Tesfahuneygn, 2015). Sedangkan di benua Asia menyebutkan bahwa 
Jurnal Ilmiah Ibnu Sina, 6(2), Oktober 2021,379-385

p-ISSN: 2502-647X; e-ISSN: 2503-1902

fasilitas Kesehatan berpengaruh terhadap keberhasilan pengobatan seperti pada negara Taiwan dan Korea dengan nilai OR sebesar 2,9 dan 1,85 (Heo, 2012; Yen, 2013). Kemudian di negara Colombia juga melaporkan bahwa fasilitas Kesehatan berpengaruh terhadap keberhasilan pengobatan dengan nilai OR sebesar 1,78 (Mateus-Solarte, 2008).

\section{KESIMPULAN}

Faktor risiko health system pada ketidakpatuhan pengobatan pasien TB Resisten Obat (RO) rendah karena bagi pasien tidak mengalami kendala dalam hal jarak ke fasilitas Kesehatan serta tenaga Kesehatan yang kompeten dalam memberikan informasi seputar pengobatan pada pasien TB RO.

\section{UCAPAN TERIMA KASIH}

Terimakasih kepada

Kementrian Pendidikan dan Kebudayaan atas Dana Hibah pada Program Penelitian Dosen Pemula.

\section{DAFTAR PUSTAKA}

Anaam, M. S., Ibrahim, M. I., Al Serouri, A. W., Bassili, A., \& Aldobhani, A. (2012). A nested case-control study on relapse predictors among tuberculosis patients treated in Yemen's NTCP. Public Health Action, 2(4), 168-173. doi:10.5588/pha.12.0044

Haynes. (1976). Strategies for Improving Compliance: A Methodologic Analysis and Review. In DL Sackett and RB. Haynes (eds.) Compliance with therapeutic regimens. Baltimore: The John Hopkins University Press.

Heo, D. J., Min, H. G. and Lee, H. H. (2012). The clinical characteristics and predictors of treatment success of pulmonary tuberculosis in homeless persons at a public hospital in busan. Korean $J$ Fam Med, 33(6), 372-380.

Kemenkes. (2018). InfoDATIN. Retrieved from Jakarta: https://pusdatin.kemkes.go.id/ resources/download/pusdatin/i nfodatin/infodatintuberkulosis-2018.pdf

Lakoh, S., Jiba, D. F., Adekanmbi, O., Poveda, E., Sahr, F., Deen, G. F., Foray, L. M., Gashau, W., Hoffmann, C. J., Salata, R. A. and Yendewa, G. A. (2020). Diagnosis and treatment outcomes of adult tuberculosis in an urban setting with high HIV prevalence in Sierra Leone: A retrospective study. Int $J$ Infect Dis, 96, 112-118.

Mateus-Solarte, J. C. a. C.-B., R. (2008). Factors predictive of adherence to tuberculosis treatment, Valle del Cauca, 
Jurnal Ilmiah Ibnu Sina, 6(2), Oktober 2021,379-385

p-ISSN: 2502-647X; e-ISSN: 2503-1902

Colombia. Int $J$ Tuberc Lung Dis, 12(5), 520-526.

Menzies, D., Dion, M. J., Francis, D., Parisien, I., Rocher, I., Mannix, S., \& Schwartzman, K. (2005). In closely monitored patients, adherence in the first month predicts completion of therapy for latent tuberculosis infection. Int J Tuberc Lung Dis, 9(12), 1343-1348. Retrieved from https://www.ncbi.nlm.nih.gov/ pubmed/16466056

Ogundele, O. A., Moodley, D., Pillay, A. W., \& Seebregts, C. J. (2016). An ontology for factors affecting tuberculosis treatment adherence behavior in sub-Saharan Africa. Patient Prefer Adherence, 10, 669. 681. doi:10.2147/PPA.S96241

Oshi, D. C., Oshi, S. N., Alobu, I. and Ukwaja, K. N. (2014). Profile, Outcomes, and Determinants of Unsuccessful Tuberculosis Treatment Outcomes among HIV-Infected Tuberculosis Patients in a Nigerian State. Tuberc Res Treat, 2014, 202983.
Tesfahuneygn, G., Medhin, G. and Legesse, M. (2015). Adherence to Antituberculosis treatment and treatment outcomes among tuberculosis patients in Alamata District, northeast Ethiopia. BMC Res Notes, 8, 503.

Trajman, A., Long, R., Zylberberg, D., Dion, M. J., Al-Otaibi, B., \& Menzies, D. (2010). Factors associated with treatment adherence in a randomised trial of latent tuberculosis infection treatment. Int $J$ Tuberc Lung Dis, 14(5), 551559. Retrieved from https://www.ncbi.nlm.nih.gov/ pubmed/20392347

WHO. (2017). Global Tuberculosis Report 2017. Retrieved from Jenewa:

Yen, Y. F., Yen, M. Y., Lin, Y. P., Shih, H. C., Li, L. H., Chou, P. and Deng, C. Y. (2013). Directly observed therapy reduces tuberculosis-specific mortality: a population-based follow-up study in Taipei, Taiwan. PLoS One, 8(11), e79644. 